\title{
Problems recruiting associates are now endemic
}

\section{By Tom King, Senior Policy Advisor, BDA}

The dental recruitment market has bounced back from the lockdown job-seeking crash, but problems with recruiting associates are now endemic across the country, new analysis from BDJ Jobs and the British Dental Association (BDA) shows. ${ }^{1}$

The first lockdown saw an expected collapse in job applications in spring 2020, but this suppression of the dental labour market activity was short-lived. BDJ Jobs data show that lockdown was followed by a boom in job-seeking activity in the summer of 2020 once routine dentistry had been restored and the job applications remain at healthy levels.

However, many of the long-term problems facing dentistry have only been exacerbated by the pandemic. Recruitment problems, previously considered to be an issue only in rural areas, now seem to be affecting major cities. Only London and the South East see a slightly more buoyant market of associates looking for work. Cities like Birmingham, Bristol, Glasgow and Leeds all now see difficulties getting associates, joining the traditional recruitment blackspots of Cumbria, Cornwall and Lincolnshire.
Statistics from BDJ Jobs applications show that NHS roles are consistently less favoured than private jobs, and for the first time in recent history, early indications from England and Wales show the NHS primary care dentist headcount is shrinking. Figures for 2020-2021 show that the number of primary care NHS dentists in England fell by 951, taking the NHS dental workforce headcount in England to its lowest level since 2013/14. This fall in the number of primary care NHS dentists in England is a departure from the pattern of the last decade, where, with the exception of 2016/17, the number of those joining NHS dentistry has slightly exceeded the numbers leaving. This will reflect the impact of the pandemic, but also the widespread unhappiness with working for the NHS. While some of these dentists may return to NHS work in the coming years, a loss of workforce capacity to this extent will certainly make it even more challenging for practices already struggling to fill NHS posts.

Despite these trends in the NHS workforce, there remain increasing numbers of dentists registered with the General Dental Council (GDC) each year and the significant fall off that many expected to see in dentists coming from Europe post-Brexit hasn't yet manifested. The proportion of registrants from the EU was $16 \%$ prior to the referendum in 2015 and remained at that level in 2020.

The number of dental care professionals (DCPs), including dental nurses, registered at 31 December 2020 has remained largely stable compared with previous years, but more recent registration reports show that the number of dental nurses has fallen off somewhat. Practices are clearly finding recruiting and retaining dental nurses a real challenge at the moment and so it is likely that the official statistics are taking a while to catch up with the reality the profession is facing.

It remains to be seen whether these trends will persist as the pandemic abates. The post-pandemic world will bring new challenges of its own, not least the substantial treatment backlog that has accumulated. Dentists will rarely have been in more demand, but can they be attracted to work in full-time NHS jobs?

\section{Reference}

1. Price A. BDJ Jobs Recruitment Whitepaper 2021. 22 December 2021. Available at: https://go.nature. com/whitepaper (accessed December 2021).

\section{Banish Blue Monday blues with wellbeing support}

Blue Monday, the third Monday in January, is said to be the most depressing day of the calendar year due to the post-Christmas

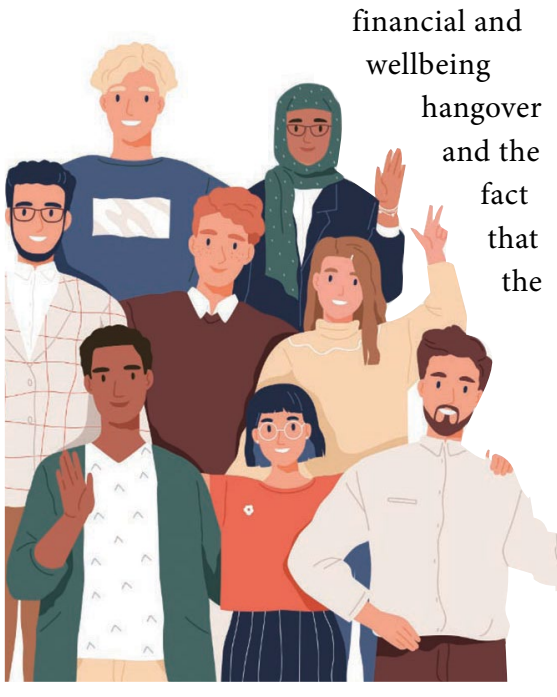

dark nights are long. Summer seems a long way off.

However, January is also the first anniversary of the launch of the Wellbeing guide for dental teams, designed to turn Blue Monday around and make it a day to focus on your wellbeing.

Since creation, the wellbeing guide has had over 10,000 page views and has been downloaded over 4,000 times. Feedback using the form on the site suggested adding more resources around menopause and these have since been added. The guide was created for all dental team members and improved by users.

The Wellbeing guide for dental teams outlines how to assess your own mental health and wellbeing and provides resources for self-care, including the range of organisations available to support you.

For a variety of reasons, there has traditionally been a reluctance amongst the dental profession to speak about and seek support for their personal problems, including mental health. It is time to put an end to that.

The guide can be downloaded at: https://www.supportfordentalteams.org/ download/.

For more information visit: https://www. supportfordentalteams.org/.

Users are encouraged to share the URL and link to it from your practice or organisation's website.

Do be sure to feedback about any improvements or additions you would like to see, and your ideas may be incorporated in the next update. 